\title{
CANDIDAL BALANOPOSTHITIS - A RETROSPECTIVE STUDY IN A TERTIARY CARE CENTRE OF SOUTH INDIA
}

\author{
Murugan Swamiappan', Vijayabhaskar Chandran², Sindhuja Ramasamy³, Sridhar V4, Sarath Chandran B5, Vanathi T6 \\ ${ }^{1}$ Assistant Professor, Department of Skin and STD, Chengalpattu Medical College, Chengalpattu. \\ ${ }^{2}$ Associate Professor, Department of Skin and STD, Chengalpattu Medical College, Chengalpattu. \\ ${ }^{3}$ Assistant Professor, Department of Skin and STD, Chengalpattu Medical College, Chengalpattu. \\ ${ }_{4}^{4}$ Assistant Professor, Department of Skin and STD, Chengalpattu Medical College, Chengalpattu. \\ 5Junior Resident, Department of Skin and STD, Chengalpattu Medical College, Chengalpattu. \\ 6Junior Resident, Department of Skin and STD, Chengalpattu Medical College, Chengalpattu.
}

\begin{abstract}
BACKGROUND

Candidal balanoposthitis is a known clinical marker and most of the time it may be the presenting feature of diabetes mellitus. It is the most common condition in uncircumcised male patients attending the sexually transmitted infections (STI) clinic in recent times as there is a decline in the tropical sexually transmitted infections.
\end{abstract}

The aim of this study is to determine the prevalence of candidal balanoposthitis in patients attending the STI clinic of a tertiary care centre.

\section{MATERIALS AND METHODS}

A retrospective chart review of the data collected from the clinical records of all patients with candidal balanoposthitis who had attended the STI clinic of Chengalpattu Medical College Hospital, Chengalpattu, Tamil Nadu, during the one year period from January 2015 to December 2015 was carried out. Demographic and clinical data were analysed.

\section{RESULTS}

The total number of patients with candidal balanoposthitis were $108(16.39 \%)$ among the total 659 male patients who attended the STI clinic during the study period. Among those, newly diagnosed diabetes mellitus were 47 (43.52\%) and known diabetes mellitus were $51(47.22 \%)$ patients. The common age group was 31 to 40 years $(44.44 \%)$. It commonly presents as preputial fissuring in young sexually active patients and glazed erythema with subpreputial discharge in sexually inactive older patients.

\section{CONCLUSION}

Candidal balanoposthitis is the most common condition in male patients attending the STI clinic. As it serves as a dependable cutaneous marker of diabetes mellitus, screening for diabetes should be done in all patients with balanoposthitis as it would help in the early diagnosis and management thereby decreasing the morbidity and improve the quality of life in them.

\section{KEYWORDS}

Balanoposthitis, Cutaneous Marker, Candidiasis, Circumcision.

HOW TO CITE THIS ARTICLE: Swamiappan M, Chandran V, Ramasamy S, et al. Candidal balanoposthitis - A retrospective study in a tertiary care centre of South India. J. Evolution Med. Dent. Sci. 2016;5(95):7042-7045, DOI: 10.14260/Jemds/2016/1592

\section{BACKGROUND \\ Balanitis is defined as the inflammation of the glans penis [1]; in uncircumcised males it is commonly associated with inflammation of the prepuce (posthitis), hence it is termed balanoposthitis.[2] It is the most common condition in uncircumcised male patients attending the sexually transmitted infections (STI) clinic in the recent times, as there is a decline in the tropical STIs due to various health programmes in creating awareness about STIs and in its management, like the syndromic management of STIs, organised by both the public and private institutions.}

Financial or Other, Competing Interest: None.

Submission 21-10-2016, Peer Review 15-11-2016,

Acceptance 21-11-2016, Published 28-11-2016.

Corresponding Author:

Vijayabhaskar Chandran,

Associate Professor,

Department of Venereology and Leprosy,

Chengalpattu Medical College, GST Road,

Chengalpattu-603001.

E-mail:buskibuski@gmail.com

DOI: $10.14260 /$ jemds/2016/1592
Balanoposthitis is due to a wide variety of causes, both infectious and non-infectious, with infection being the most frequent and several microorganisms reported. Approximately, $3 \%$ of uncircumcised men are affected globally [3] and in $11 \%$ of the patients attending STI clinic. ${ }^{[1,3,4]}$ Candidal balanoposthitis is a well-recognised condition, first described by Engman in 1920,[5] being the most common infection which is responsible for up to $30-35 \%$ among the infectious balanitis.[6-8]

Candidal balanoposthitis is a known cutaneous marker of diabetes mellitus; other predisposing factors include uncircumcision, congenital and acquired phimosis, urinary incontinence and immunosuppression [8-10]. Uncircumcision is considered to be a major risk factor for candidal balanoposthitis when associated with poor genital hygiene, buildup of smegma and tight foreskin.[11]

Diabetes mellitus, the most challenging public health problem of $21^{\text {st }}$ century with a worldwide prevalence of 387 million (8.3\%) and predicted to be 592 million by $2035.77 \%$ of people with diabetes live in low and middle income countries. India, once known as the "diabetes capital of the world" was home to 61.3 million patients with type 2 diabetes 
mellitus in 2011 with predictions of 101.2 million diabetics by 2030. India is second only to China which is home to 92.3 million diabetics.[12]

Candidal balanoposthitis can be the first clinical sign of diabetes mellitus in an apparently healthy male and the diagnosis of diabetes mellitus was made for the first time in $8 \%$ of these patients.[10] Diabetes causing candidal balanoposthitis is more of a problem in India than sexually acquired balanoposthitis.

Patients with candidal balanoposthitis commonly present with local burning or pruritus, difficulty in coitus or retracting the prepuce for urination and cleansing. On examination, mild glazed erythema or erosion, papules with or without satelliteeroded pustules, subpreputial discharge and fissuring of the prepuce $[1,3,6,10,11]$ occurs. The diagnosis is mostly based on the clinical examination.

Preputial fissuring, a characteristic feature of this condition is a result of the alteration in biomechanical properties of skin like elasticity and loss of surface lipids due to impairment of sebaceous gland activity resulting in reduced hydration [10, 13]. Advanced glycation end products (AGEs) [10, 13] content is increased in skin of diabetics with poor glycaemic control. AGEs impair production of collagen and extracellular organization that is associated with a lowered hydroxyproline content and superoxide dismutase activity resulting in the impairment of biomechanical properties, elasticity and hydration. Biomechanical stress due to repeated acts of retracting the prepuce during urination and coitus can result in fissuring which can lead to fibrosis and phimosis.

\section{Aim}

To determine the prevalence of candidal balanoposthitis in patients attending the STI clinic of a tertiary care centre.

\section{MATERIALS AND METHODS}

A retrospective chart review of the data collected from the clinical records of all patients with candidal balanoposthitis who had attended the sexually transmitted infection (STI) clinic of Chengalpattu Medical College Hospital, Chengalpattu, Tamil Nadu, during the one year period of 2015 was carried out. Age, marital status, sexual orientation, history of STIs, concomitant diseases, $\mathrm{KOH}$ smear examination, final diagnosis, prescribed treatment and followup data were collected. The diagnosis of candidal balanoposthitis was established on the basis of the presence of fissuring on the prepuce, generalised or patchy glazed erythema with or without erosion on the glans or under the prepuce, subpreputial exudates and $\mathrm{KOH}$ examination for pseudohyphae. All patients were also tested for syphilis and human immunodeficiency virus (HIV), according to the standard protocol of our STI clinic.

\section{RESULTS}

The total number of male patients attended the STI clinic were 659 during the study period of one year from January 2015 to December 2015. Among that candidal balanoposthitis was seen in $108(16.39 \%)$ patients [Table-1].

The maximum number of patients with candidal balanoposthitis were in the 30 - 40 age group (44.44\%). The next predominantly affected were the $41-50$ years $(21.30 \%)$ followed by the $20-30$ years (13.89\%) age group [Table-2].
All the patients with candidal balanoposthitis were uncircumcised (108-100\%) and majority of them are married (100 - 92.59\%) having regular coitus with their spouse. Promiscuous behaviour was seen in 43 (39.81\%) patients and rest of them 65 (60.19\%) patients denied it [Table-3]

The blood sugar levels were elevated in 98 (90.74\%) patients and it was found to be normal in 10 (9.26\%) patients. Among that known diabetics were 51 (47.22\%) patients and newly diagnosed were 47 (43.52\%) patients [Table-4].

The presenting complaints of these patients with candidal balanoposthitis were preputial fissuring, itching, pain, burning sensation, burning micturition, painful coitus, inability in retracting the prepuce, phimosis, depigmentation and subpreputial discharge. On examination glazed erythema, erosion, papules with or without satellite-eroded pustules, ulcers over the glans and prepuce were seen. Among that preputial fissuring was predominantly seen in 103 (95.37\%) patients followed by genital itching in $30(27.78 \%)$ patients. Clinical features like with glazed erythema and erosion without preputial fissuring was seen in patients of age more than 61 years in whom the sexual activity is minimal.

STIs, other than candidal balanoposthitis, among the male STI clinic attendees seen were syphilis $4(0.61 \%)$, genital wart 17 (2.58\%), genital herpes 11 (1.67\%), urethral discharge 2 $(0.30 \%)$ and HIV 23 (3.49\%). Non-venereal genital dermatoses which included balanitis of various other causes, both infective and non-infective, like Zoon's balanitis and normal skin variants like pearly penile papules were seen in $53(8.04 \%)$ patients. $441(66.92 \%)$ patients were asymptomatic and visited the clinic for screening [Table-5].

\begin{tabular}{|c|c|c|}
\hline $\begin{array}{c}\text { Total No. of } \\
\text { New Male } \\
\text { Cases During } \\
\text { the year 2015 }\end{array}$ & $\begin{array}{c}\text { Total No. of } \\
\text { Candidal } \\
\text { Balanoposthitis }\end{array}$ & $\begin{array}{c}\text { Percentage of } \\
\text { Patients with } \\
\text { Candidal } \\
\text { Balanoposthitis }\end{array}$ \\
\hline 659 & 108 & $16.39 \%$ \\
\hline \multicolumn{2}{|c|}{ Table 1: Incidence of Candidal Balanoposthitis during } \\
the Year 2015
\end{tabular}

\begin{tabular}{|c|c|c|}
\hline $\begin{array}{l}\text { Age Group } \\
\text { (Years) }\end{array}$ & $\begin{array}{l}\text { No. of Patients with } \\
\text { Balanoposthitis }\end{array}$ & Percentage \\
\hline $20-30$ & 15 & $13.89 \%$ \\
\hline $31-40$ & 48 & $44.44 \%$ \\
\hline $41-50$ & 23 & $21.30 \%$ \\
\hline $51-60$ & 14 & $12.97 \%$ \\
\hline$>61$ years & 8 & $7.40 \%$ \\
\hline Total & 108 & $100 \%$ \\
\hline \multicolumn{3}{|c|}{$\begin{array}{c}\text { Table 2. Age Distribution of Patients with Candidal } \\
\text { Balanoposthitis }\end{array}$} \\
\hline
\end{tabular}

\begin{tabular}{|c|c|c|}
\hline \multirow{2}{*}{ Marital Status } & Married & $100(92.59 \%)$ \\
\cline { 2 - 3 } & Unmarried & $7(6.48 \%)$ \\
\cline { 2 - 3 } & Separated & $1(0.96 \%)$ \\
\hline \multirow{2}{*}{ Promiscuous Behaviour } & Present & $43(39.81 \%)$ \\
\cline { 2 - 3 } & Denies & $65(60.19 \%)$ \\
\hline \multirow{2}{*}{ Circumcision } & Circumcised & $0(0 \%)$ \\
\cline { 2 - 3 } & Uncircumcised & $108(100 \%)$ \\
\hline \multirow{2}{|c|}{ Table 3. Sexual Behaviour/Circumcision in Patients } \\
with Candidal Balanoposthitis \\
\hline
\end{tabular}




\begin{tabular}{|c|c|c|c|}
\hline $\begin{array}{c}\text { Known } \\
\text { Diabetic }\end{array}$ & $\begin{array}{c}\text { Newly } \\
\text { Diagnosed } \\
\text { Diabetic }\end{array}$ & $\begin{array}{c}\text { Patients with } \\
\text { Normal Blood } \\
\text { Glucose Levels }\end{array}$ & Total \\
\hline 51 & 47 & 10 & 108 \\
$(47.22 \%)$ & $(43.52 \%)$ & $(9.26 \%)$ & $(100 \%)$ \\
\hline
\end{tabular}

Table 4. Diabetic Status of the Patients with Candidal Balanoposthitis

\begin{tabular}{|c|c|}
\hline Disease & $\begin{array}{c}\text { Total No. of } \\
\text { Cases } \\
\text { (Percentage) }\end{array}$ \\
\hline Syphilis & $4(0.61 \%)$ \\
\hline Genital wart & $17(2.58 \%)$ \\
\hline Genital herpes & $11(1.67 \%)$ \\
\hline Urethral discharge & $2(0.30 \%)$ \\
\hline $\begin{array}{l}\text { Human immunodeficiency virus } \\
\text { (HIV) }\end{array}$ & $23(3.49 \%)$ \\
\hline Candidal balanoposthitis & $108(16.39 \%)$ \\
\hline Non-venereal genital dermatoses & $53(8.04 \%)$ \\
\hline Asymptomatic/Screening & $441(66.92 \%)$ \\
\hline \multicolumn{2}{|c|}{$\begin{array}{c}\text { Table 5. Disease Wise Distribution of Male Patients whe } \\
\text { Attended the STI Clinic During the Year } 2015\end{array}$} \\
\hline
\end{tabular}

\section{DISCUSSION}

Candidal balanoposthitis is undoubtedly the most common condition in STI clinic attendees among males as our study shows an incidence of $16.39 \%$ which is far ahead of other venereal and non-venereal conditions. Similar higher incidence of candidal balanoposthitis had been reported by Sharma et al,[14] Arakkal et al,[15] Murugesh et al[16] and Siddappa et al.[17] Its occurrence was found to be more common in the sexually active younger age group but a significant number of older patients above the age of 61 years were also affected as older age is one of the risk factor for it. [9]

Diabetes mellitus was found to be the predisposing factor in $90.74 \%$ of our patients with candidal balanoposthitis. The diabetic status was previously known in $47.22 \%$ of patients. Diabetes mellitus was newly diagnosed in a substantial number of $43.52 \%$ of our patients who presented with the initial manifestation of candidal balanoposthitis; from this it is evident that it is a certain cutaneous marker of diabetes mellitus.

All our patients with candidal balanoposthitis were uncircumcised. Circumcision in India is considered a religious or cultural identity and it is not routinely done.[18-20] Uncircumcision and maintenance of poor genital hygiene due to lack of awareness in cleansing after retracting foreskin is a contributing factor to candidal balanoposthitis in our patients. Although the carriage of the yeast on the penis is common, being $14-18 \%$, with no significant differences between carriage rate in circumcised and uncircumcised, symptomatic infection is more common in the uncircumcised male.[21,22]

Preputial fissuring considered to be a specific sign of undiagnosed diabetics [13] is the common presentation in our patients with candidal balanoposthitis, $95.37 \%$ presented with it. It is due to biomechanical stress as a result of coitus or retracting the prepuce for cleansing or urination. This feature is not found in older sexually inactive patients, they present with glazed erythema on the glans penis and subpreputial discharge.
Candidal balanoposthitis is a treatable condition; early diagnosis may help in appropriate management and screening for diabetes mellitus and enables early management of it, thus reducing long-term morbidity and complications. Strict glycaemic control and maintenance of proper genital hygiene aids to prevent recurrences of balanoposthitis thus avoiding operative complications like phimosis.

\section{CONCLUSION}

Candidal balanoposthitis is the most common condition in male patients attending the STI clinic. As it serves as a dependable cutaneous marker of diabetes mellitus, screening for diabetes should be done in all patients with balanoposthitis as it would help in the early diagnosis and management thereby decreasing the morbidity and improve the quality of life in them.

\section{REFERENCES}

1. Edwards S. Balanitis and balanoposthitis: a review. Genitourin Med. 1996;72(3):155-9.

2. Waugh MA. Balanitis. Dermatologic Clinics. 1998;16:7572.

3. Rajiah K, Veettil SK, Kumar S, et al. Study on various types of infections related to balanitis in circumcised or uncircumcised male and its causes, symptoms and management. Afr J Pharm Pharmacol. 2012;6(2):74-83.

4. Birley HD, Walker MM, Luzzi GA, et al. Clinical features and management of recurrent balanitis: association with atopy and genital washing. Genitourin Med. 1993;69(5):400-3.

5. Engman MF. A peculiar fungus infection of the skin (soorpilze?). Arch Dermatol Syphilol. 1920;1(4):370-374.

6. Dockerty WG, Sonnex C. Candidal balanoposthitis: a study of diagnostic methods. Genitourin Med. 1995;71(6):407409.

7. Abdullah AN, Drake SM, Wade AA, et al. Balanitis (balanoposthitis) in patients attending a department of genitourinary medicine. Int J STD AIDS. 1992;3(2):128-9.

8. Lisboa C, Ferreira A, Resende C, et al. Infectious balanoposthitis: management, clinical and laboratory features. Int J Dermatol. 2009;48(2):121-4.

9. Lisboa C, Santos A, Dias C, et al. Candida balanitis: risk factors. J Eur Acad Dermatol Venereol. 2010;24(7):820-6.

10. Verma SB, Wollina U. Looking through cracks of diabetic candidal balanoposthitis. Int J Gen Med. 2011;4:511-3.

11. Achkar JM, Fries BC. Candida infections of the genitourinary tract. Clin Microbiol Rev. 2010;23(2):25373.

12. Gupta M, Singh R, Lehl SS. Diabetes in India: a long way to go. Int J Sci Rep. 2015;1(1):1-2.

13. Huang YC, Huang YK, Chen CS, et al. Phimosis with preputial fissures as a predictor of undiagnosed type 2 diabetes in adults. Acta Derm Venereol. 2016;96(3):37780.

14. Sharma S, Tiwari S, Paliwal V, et al. Study of patterns of sexually transmitted diseases using a syndromic approach in the era human immunodeficiency virus from a tertiary care hospital of the northern India. Indian J Sex Transm Dis. 2015;36(2):158-61. 
15. Arakkal GK, Damarla SV, Kasetty HK, et al. Changing trends in sexually transmitted infection clinic (STI) attendees - Current scenario. Int J Med Sci Public Health. 2014;3(10):1215-8.

16. Murugesh SB, Sugareddy, Raghunath S. Pattern of sexually transmitted diseases at Davangere. Indian J Sex Transm Dis. 2004;25(1):9-12.

17. Siddappa K, Kumar VJ, Ravindra K. Pattern of STDs at Davangere. Indian J Sex Transm Dis. 1990;11(2):39-42.

18. Chandhiok N, Gangakhedkar RR. Roundtable: the new evidence on male circumcision: an Indian perspective. Reproductive Health Matters. 2007;15(29):53-6.
19. Madhivanan P, Krupp K. Doesn't the public have the right to know that male circumcision protects against HIV? Indian Journal of Medical Ethics. 2009;6(1):5-6.

20. Madhivanan $P$, Krupp $K$, Chandrasekaran $V$, et al. Acceptability of male circumcision among mothers with male children in Mysore, India. AIDS. 2008;22(8):983-8.

21. Davidson F. Yeasts and circumcision in the male. $\mathrm{Br} \mathrm{J}$ Venereal Dis. 1977;53(2):121-2.

22. Rodin P, Kolator B. Carriage of yeasts on the penis. Br Med J. 1976;1(6018):1223-4. 